\title{
Why Green Products Remain Unfavorable Despite Being Labelled Environmentally-Friendly?
}

\author{
Weng Marc Lim \\ Monash University \\ E-Mail: lim.weng.marc@monash.edu \\ Ding Hooi Ting \\ Monash University \\ E-Mail: ting.ding.hooi@monash.edu \\ Woo Kan Ng \\ Monash University \\ E-Mail: wkng25@student.monash.edu \\ Jin How Chin \\ Monash University \\ E-Mail: jhchi6@student.monash.edu \\ Wei-Xiang Alexander Boo \\ Monash University \\ E-Mail: waboo2@student.monash.edu
}

\begin{abstract}
Although green products have been widely recognized as being environmentally-friendly, actual consumer adoption, purchases and consumption of green products have been disappointing. Instead, consumption of products which is causing harmful impacts on the environment is gaining further momentum. Such a phenomenon is detrimental to environmental sustainability and therefore requires immediate attention and corrective action. This paper seeks to understand the failure of green products in the marketplace and subsequently provide informed recommendations to stakeholders to remedy the situation. The study is exploratory in
\end{abstract}


nature and uses qualitative in-depth interviews to understand consumer perception on green products. Findings suggest that there is a lack of understanding about green products and environmental sustainability, ignorance, and low customer delivered value of green products. Implications and recommendations from the findings are also presented.

Keywords: Green Products, Environmentally-Friendly, Environmental Sustainability, Consumer Behavior

\section{INTRODUCTION}

Environmental deterioration has become a major societal concern in the contemporary era, in which such a concern has given birth to an environmental-based concept - green marketing. Green marketing refers to a set of marketing efforts designed to generate and facilitate any exchanges intended to satisfy human needs or wants, such that the satisfaction of these needs and wants occur, with minimal detrimental impact on the natural environment (Polonsky, 1994). This novel concept is gaining much visibility and is becoming a major consideration for the corporate community (Gurau and Ranchod, 2005). While many organizations are starting to incorporate the green concept into their production and operations, what remains as a significant problem in the society is the lack of continuous interest in green products. This study attempts to address this issue by understanding why green products remain unfavourable despite being labelled as environmentally-friendly. To facilitate such an understanding, an exploratory study is carried out using qualitative interviews to understand consumer perception of environmentally-friendly products. Notably, such an investigation will contribute in two ways: (i) to theory - rationales behind consumers' reluctance to purchase and consume green products (i.e. why it is unfavourable); and (ii) to practice - what can governments and organizations do to foster favourable perceptions and attitudes towards purchasing and consuming environmentally friendly products. This study is different than prior studies in the literature as insights towards targeted understandings is through actual consumer responses, in which recommendations are also based on what consumers perceive and believe to be able to initiate a change in them and others in the society to adopt green consumerism and foster green purchases and consumption.

\section{METHOD}

The current study is exploratory in nature as it seeks to understand consumer perceptions on green products in the light of unfavorable attitudes towards green 
products. Qualitative in-depth interviews were employed as thorough perceptual insights are attainable through this research method. 20 informants were randomly selected through mall-intercept systematic sampling in Klang Valley, Malaysia. Klang Valley was chosen as it is a satellite town of the Malaysian capital that comprises of both urban and suburban community and hence, making it the most strategic location among the 14 states in the country (Euromonitor, 2011), and has been argued to be a good location of study in various studies in the Malaysian context (e.g. Lim and Ting, 2012a; 2012b). No demographic criteria were set and participation was voluntary. 12 males and 8 females participated in the interviews. The analysis was carried out using the interpretive approach, that is, through engaging the process of inductive reasoning and balancing description with insightful interpretation, including testing and challenging preliminary interpretations, and conceptualizing a coherent final product. Initial analyses were discussed with scholars in the field of green marketing and environmental sustainability. The final findings are presented in the following section.

\section{FINDINGS AND DISCUSSION}

\section{Lack of Understanding}

Most consumers believe that they understand the term 'green' and the purpose of green products. However in reality, this is not the case. Their claims and believes were, in fact, limited (i.e. only basic understanding). Such an understanding was not thorough enough to realize the power and influence of green products on the environment. For example, a factory manufactures a product which possesses green qualities, such as bio-degradability and green energy consumption, but in the expense of toxic gas emission. Scholars would argue that such production does not constitute as a green product but many consumers disagreed. Most consumers overlooked the production and manufacturing process. When consumers were asked what they understood about the term 'green product':

'Green product is a product which is environmental friendly, not bringing harm to the earth or whatsoever.'

Clearly, such responses imply that consumers are only aware of the consequences caused by the usage of the product itself. They do not take into account for situations and attributes that the products undergo in the production and manufacturing process.

Interestingly, a common perception towards green products is that it has to be recyclable. Products that have the ability to be recycled do not necessarily make them a green product as its production and manufacturing process could have been 
detrimental to the environment. This suggests that a misconception subsides within minds of the consumers.

'Something that can be recycled or reused or things that is made from non-toxic materials.'

To be exact, only one respondent was deemed to have a good understand on the meaning and purpose of green products.

'Green product is a product that can be produced in a sustainable and environmentally-friendly way and has low carbon foot print.'

\section{Ignorance}

From the interviews, many consumers are observed to be ignoring environmental issues and are reluctant to consider efforts for improving environmental conditions. Findings suggest that this is due to the obsession of enhancing their own lives thereby neglecting issues that does not concern to their direct well-being. According to Hardisty and Weber (2009), when personal benefits are taken into the equation, it is very difficult to make a correct decision in terms of what is right - whether benefits to personal gain is right or whether saving the environment is right or which of the two takes precedence to what is right. When asked about the things that shape such a consideration about the self and the environment, consumers argued:

'Human ignorance. End of the day, it boils down to how we manage our resources and our attitude towards building a greener future. But, we really don't care. There are much more important issues to deal with.'

'I just don't have the time, energy to actually even consider about the environment. To be honest, I will only care about the environment if there is some hot chick who I really like that is some environmental freak.'

Many consumers in contemporary times are so obsessed with their work and relationship that they chose not to care and neglect the environment. To these consumers, an effort done (e.g. purchases and consumption of green products) by only one person will not have any significant effects on the environment. In particular, these consumers think that their effort will not help much and therefore chose to ignore the environment. Further, they believe that there are always other dedicated environmentalists out there who would take care of the environment passionately and it is best to leave the job of saving the environment to this segment of consumers.

Whereas, some consumers claim that although they do not initiate or engage in 
any environmental efforts to improve the quality of current environment, they still believe that they are caring for the environment as they are not contributing towards any harmful actions towards the environment. They remain ignorant of the fact that many non-green products in the market have detrimental effects on the environment.

'At the very least I don't go out of my way to damage it. So, I think it doesn't really matter whether I purchase or don't purchase green products.'

\section{Environmental Solution or Marketing Opportunity}

Green products have emerged to be a very promising environmental solution towards environmental sustainability. The market for green products is growing, but at the same time, organizations are seeing this as a marketing opportunity to make more profits and as a result, many organizations are observed to place a high price tag on green products. More often than not, these organizations often attribute the high price to the high cost of production, in which many consumers feel unjust. Furthermore, the problem of green-washing or green selling has become a concern to consumers, whereby the problem basically indicates that the so-called green product has not been incorporated with authentic green qualities and sold with merely green labels with the premium prices (Lee, 2008). As a result, many consumers become reluctant to purchase green products due to the risk associated with green products - there is a high chance that it turns out to be a scam. Human greed, therefore, possesses the greatest threat in halting the progress of green products. When consumers were asked for their opinions on whether organizations are making a lot of money by offering green products and whether such offerings are indeed authentic, consumers argued:

'Whether or not they turn a profit introducing green products is irrelevant. The fact is they are only doing things that satisfy their shareholders. There is little difference between selling environmentally friendly products and standard products. The only distinction is their intended target.'

Nonetheless, consumers do believe that there are genuine organizations that are seeking a perfect balance between environmental solutions and marketing opportunity for their manufactured green products which would result in a win-win situation for both the environment and shareholders as mentioned by one of the respondents in such a way:

'In my opinion, it might be both profit making yet remain sincere in offering green products, because as the term "green" is getting more emphasized 
nowadays, the producers will start producing more and more green products as by doing so they get the attentions of the consumers and thus making good image for the company and increasing its "credibility" in the consumers' eyes. Moreover, they will get the support of the government in terms of subsidizing, tax exemption and so on. This is like killing a lot of birds with just a stone. However, I feel that marketing opportunity has a stronger motivation for the company to produce green product over environmental solution.'

\section{Low Customer Delivered Value}

Contemporary consumers are becoming wiser in their purchase decisions in the sense that they are constantly seeking for alternatives that provide them with maximum customer delivered value (Gotlieb et al., 1994). Customer delivered value is the difference between prospective customer's evaluation of all benefits and costs of an offering compared with perceived alternatives. Although green products possess distinctive product value which includes its green qualities, these unique green qualities are often overlooked by consumers. This leads to a lower overall product value attributed to green products. More often than not, prices of green products tend to be higher than normal products with similar functions and this would inject extra monetary cost on customer pockets. To make matters worse, some consumers reveal experiences suggesting that green products often fail to function as well as normal products. When asked whether consumers consider green products as alternatives when shopping, consumers' responded:

'To be honest, I will still put the functionality and effectiveness and price of a product as the priorities to my decision of making purchases. As such, I would not consider green products as alternatives when I go shopping as they are often pricey and do not provide much functionality as compared to normal products.'

Besides, the market of green products is deemed to be quite new to consumers and the brand would usually be anonymous to most of the buyers as compared to the prestigious brands of normal products which has been around the market for long period of time. Hence, the image value provided by the branding of green products would be much lower.

'People don't even recognize how expensive the product is because it looks so normal. In fact, because most green products have no brand, people often think it's some cheap product. It looks bad on me!' 


\section{IMPLICATIONS AND RECOMMENDATIONS}

Findings from the study suggest several implications to theory and recommendations for practice that can be adopted by governments and organizations to foster favorable perceptions, attitudes and behavioral changes towards purchasing and consuming environmentally-friendly products.

On the consumer side, the study argues that consumers have a lack of understanding of what is meant by green products as consumers only evaluated a product to be green based on the final product itself without evaluating production and manufacturing processes. Because of such limited understanding, consumers are not able to see the potentially fruitful impact of purchasing and consuming green products towards environmental sustainability. Further, the misconception of green products with recyclable products poses a threat to authentic green products. In particular, authentic green products has to be environmentally friendly from its inception in the production and manufacturing process right until the disposal of the products, which could either be bio-degradable or recyclable, and not just limited to recyclability. There is also existence of ignorance in consumer minds. More specifically, consumers were found to be ignorant as: (i) they believe efforts, such as purchasing and consuming green products, from one person will have no significant effect on the environment; (ii) personal well-being is more important and environmental well-being is less important, in which environmental well-being becomes important only when it affects consumers' personal well-being; and (iii) efforts to save the environment should be left to environmentalist. Such ignorance is translated into a 'not-bothering' attitude towards green products. This contributes to a lack of demand and non-existence of favorable perceptions and attitudes toward green products.

On the marketing side, green product offerings are pre-dominantly viewed as a marketing opportunity rather than an environmental solution. In particular, the positioning of green products in the eyes of target segments is viewed as profit-oriented. This is mainly attributed to the high price tags attached to green products. Coupled with the existence of many non-authentic green producers, the phenomena of green-washing arise, which transmit messages of deception that is formed in consumer minds. Good green producers ought to understand that there needs to be a balance between profits and providing an authentic environmental solution that makes consumers feel that they are contributing to environmental sustainability, and not merely putting green labels and charging unjust premium prices. Besides that, existing green products are not providing good customer 
delivered value. While premium prices are charged, the functionality of non-green products remains superior and is attached with a relative less expensive price tag. Green qualities are often overlooked by consumers and more materialistic considerations, such as brand value, are not provided. Despite knowing that green products are environmentally-friendly and aid towards environmental sustainability, these situations, clearly, have contributed to unfavorable consumer attitudes towards green products.

To ensure environmental sustainability, every member of the society has a role to play (Grant, 2008). The cooperation between consumers, organizations and government is vital to materialize visions for environmental sustainability (Stephen et al., 1996), in which the purchase and consumption of green products has been strongly encouraged. On the governmental side, governments could introduce new regulations and more tempting incentives in order to reduce harmful products as well as encourage more organizations to innovate and offer green products in the marketplace. This thought is shared by consumers in this study. Consumers believe that bans on harmful products and tax privileges and subsidies are essential to promote the development of green products.

'Some transition strategies that can make everyone use green product is vital. If green products can really replace the harmful products then ban those harmful products and create some policy that states that those green products must be used. NO point introducing some product that people doubt its credibility and still letting those 'harmful' products to be used widely.'

From consumer responses, it is clear that governments can play an imperative role towards the promotion of green products and environmental sustainability. In fact, many organizations have expressed a desire to venture into the green industry but are often halted by the high cost of production. In this case, incentives from the government would aid towards the development of the green product industry in terms of setting up and manufacturing costs. Nonetheless, prior findings indicate that consumers have doubts on the authenticity of green products as they were afraid of being the victim of 'green-washing'. Caution should therefore be noted as some unethical organizations may take this as an opportunity to scam the incentives. A group of intelligence should be established to ensure that the incentives distributed are appropriately channelled to the production and advancement of green products which meets international standards for green products. Furthermore, regulatory certified labels for green products could also be introduced for qualified green products. While 
introducing new regulations has not been the easiest thing for any government, after all, evidence have shown its positive effects on consumer culture and the environment (e.g. no plastic bags days, no more free plastic bags, replanting trees after cutting them down and etc). Governments can also impose new laws penalizing organizations that are involved in 'green-washing' and also to those that are causing detrimental effects in their production and manufacturing processes to the environment. Public awareness campaigns are also encouraged to educate consumers about the benefits of green products and the aftermath effects if environmental sustainability is taken lightly (Demers et al., 1997).

On the organizational side, it is imperative for green producers to understand the shortcomings of consumer unfavorable perception towards green products. One of the reasons behind consumers' reluctance to purchase green products is due to price and quality. Consumers today often see functionality as the highest priority in purchasing decisions. It is therefore important for green producers to ensure that green products produced offer functions that are of a comparable standard, if not better, than non-green products. Innovative functionality is also an alternative to provide a distinction between green products and non-green products. Further, green producers are encouraged to price green product offerings at a competitive level as normal commercial products in prior to the incentives from government. A going-rate pricing under competition-based pricing can be considered by the marketers of green producers. As found through the current study, consumers are more likely to consider green products as alternatives provided the price difference is reasonable. Nonetheless, what is deemed to be reasonable in one culture may not be reasonable in another culture, and thus, future research can look at this area to provide more specific recommendations in terms of pricing strategies for green products. Besides that, Camino (2007) suggests that organizations need to understand customer value thoroughly and strive to increase the perceived value in consumer minds. In contemporary times, image value is gaining much importance as it is vastly sought modern consumers. The term 'green' imposes a very dull and boring image of green products to consumers. Organizations, therefore, are encouraged to focus on branding strategies and develop brand profiles for green products (Griskevicius et al., 2010), as many consumers found that green products often do not have a recognizable brand and are often view by others in the society as 'just an ordinary product', in which consumers consequently feel that the premium prices charged becomes unjust. When consumers were asked in what way green products would appear more appealing, consumers suggested: 
'It must be creative so that it looks interesting.'

'Branding is a must!'

Advertisement plays a big role in injecting awareness and impact of green products to the environment. Although there are many green product advertisements, very few have caught the eyes of consumers and hence many consumers are not aware of the issue regarding the ill-environment. Lack of quantity is certainly not the case but lack of quality is there to be seen. Most consumers reported that they are aware of the existence of green advertisements but most of them denied that they are influenced by the existing advertisements. Governments and green producers should take note of this situation and produce more appealing advertisements that is designed to catch the attention of their target market (Prakash, 2002). Since contemporary consumers live in a digital age, advertisements on social networks and interactive media promotional efforts are viable options to connect to the target market of green products in a more contemporary, appealing manner. Promotions, such as discounts and rebates, should also be introduced to promote green products, which is not only for the sake of survivability in the marketplace, but also, to attract more consumers who are curious and are afraid of experimenting new products to try green products. Nonetheless, future research is very much needed from time to time to improve green marketing strategies. The addition of the current findings to the extant environmental marketing literature suggests that additional work on profiling (and segmentation) should focus on psychographics, rather than more traditional (i.e. demographic) methods. As the environmental movement continues to mature, it is important that segmentation criteria be periodically investigated to validate their use in light of changes taking place (Straughan and Robert, 1999)

\section{REFERENCES}

Camino, R. J. (2007). Re-evaluating green marketing strategy: a stakeholder perspective. European Journal of Marketing, 41(11/12), 1328-1358.

Demers, I., Pelletier, L. G., and Ménard, S. C. (1997). The impact of behavioural difficulty on the saliency of the association between self-determined motivation and environmental behaviours. Canadian Journal of Behavioural Science, 29(3), 157-166.

Euromonitor. (2011). Consumer lifestyles in Malaysia. Retrieved, January, 5, 2012, from Euromonitor International database. 
Gotlieb, J. B., Grewal, D., and Brown, S. W. (1994). Consumer satisfaction and perceived quality: complementary or divergent constructs? Journal of Applied Psychology, 79(6), 875-885. http://dx.doi.org/10.1037//0021-9010.79.6.8755.

Griskevicius, V., Tybur, J. M., and Van den Bergh, B. (2010). Going green to be seen: status, reputation, and conspicuous conservation. Journal of Personality and Social Psychology, 98(3), 392-404. http://dx.doi.org/10.1037/a0017346.

Grant, J. (2008). Green Marketing. Strategic Direction, 24(6), 26-27. http://dx.doi.org/10.1108/02580540810868041.

Gurau, C. and Ranchod, A. (2005). International green marketing: A comparative study of British and Romanian firms. International Marketing Review, 22(5), 573-586. http://dx.doi.org/10.1108/02651330510624381.

Hardisty, D. J. and Weber, E. U. (2009). Discounting future green: money versus the environment. Journal of Experimental Psychology, 138(3), 329-340.

Lee, K. (2008). Opportunities for green marketing: young consumers. Marketing Intelligence and Planning, 26(6), 573-586.

Lim, W. M. and Ting, D. H. (2012a). E-shopping: an analysis of the technology acceptance model. Modern Applied Science, 6(4), 49-62. http://dx.doi.org/10.5539/mas.v6n4p49.

Lim, W. M. and Ting, D. H. (2012b). E-shopping: an analysis of the uses and gratifications theory. Modern Applied Science, 6(5), 48-63. http://dx.doi.org/10.5539/mas.v6n5p48.

Polonsky, M. J. (1994). An introduction to green marketing. Electronic Green Journal, 1(2), 2-3.

Prakash, A. (2002). Green marketing, public policy and managerial strategies. Business Strategy and the Environment, 11(5), 285-297. http://dx.doi.org/10.1002/bse.338.

Stephen, J., Randy, K., and Lorient, F. A. (1996). Visions for environmental sustainability. Munich: Ballak and Co.

Straughan, R. D. and Robert, J. A. (1999). Environmental segmentation alternatives: a look at green consumer behavior in the new millennium. Journal of Consumer Marketing, 16(6), 558-575. http://dx.doi.org/10.1108/07363769910297506. 
